Engineer Research and

Development Center

Engineering for Polar Operations, Logistics, and Research (EPOLAR)

\title{
Changes in the Albedo of the Pegasus and Phoenix Runways, 2000-2017
}

Elias J. Deeb, Blaine F. Morriss, Steven F. Daly, July 2017 and Robert B. Haehnel

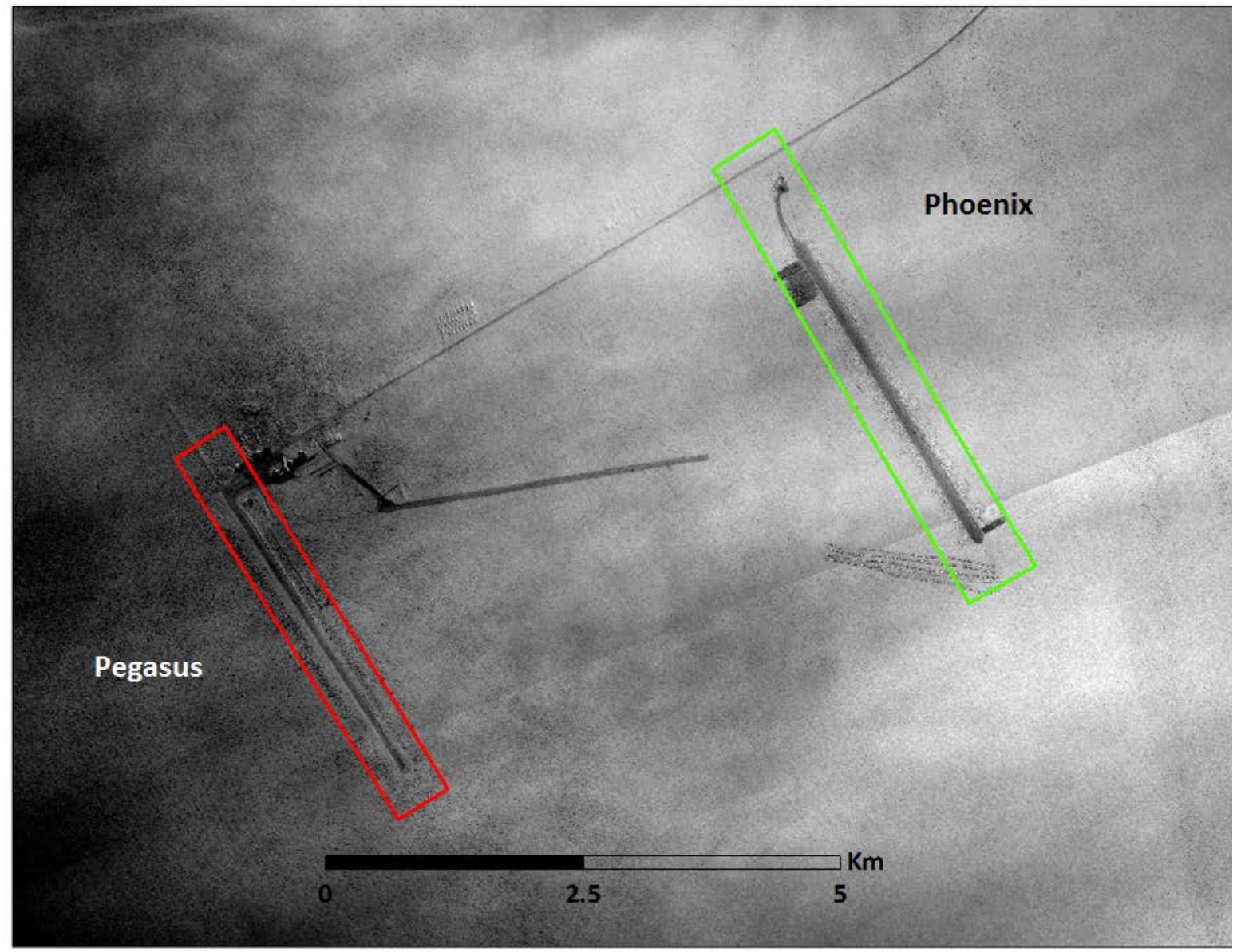


The U.S. Army Engineer Research and Development Center (ERDC) solves the nation's toughest engineering and environmental challenges. ERDC develops innovative solutions in civil and military engineering, geospatial sciences, water resources, and environmental sciences for the Army, the Department of Defense, civilian agencies, and our nation's public good. Find out more at www.erdc.usace.army.mil.

To search for other technical reports published by ERDC, visit the ERDC online library at http://acwc.sdp.sirsi.net/client/default. 


\section{Changes in the Albedo of the Pegasus and Phoenix Runways, 2000-2017}

Elias J. Deeb, Blaine F. Morriss, Steven F. Daly, and Robert B. Haehnel

U.S. Army Engineer Research and Development Center (ERDC)

Cold Regions Research and Engineering Laboratory (CRREL)

72 Lyme Road

Hanover, NH 03755-1290

Final Report

Approved for public release; distribution is unlimited.

Prepared for National Science Foundation, Office of Polar Programs, Antarctic Infrastructure and Logistics

Arlington, VA 22230

Under Engineering for Polar Operations, Logistics, and Research (EPOLAR) EP-ANT-16-24, "Historical Albedo Assessment for Alpha Site Runway using Remote Sensing" 


\section{Abstract}

Albedo is the ratio of total hemispherical reflected (upwelling) to incoming (downwelling) radiative flux (or irradiance) at a surface. For operations on the McMurdo Ice Shelf, Antarctica, albedo is a controlling factor. Impurities such as dust, soot, mineral, and other organic deposits on a snow or ice surface can dramatically lower albedo, increase solar energy absorption in the ice shelf, and significantly alter the energy balance, resulting in increased melting, snow density variations, and compromised structural integrity of the snow and ice matrix. The occurrence of such impurities at Pegasus Runway may have been a factor in its decline and replacement with the Phoenix Runway in the 2016- 2017 field season. Therefore, the National Science Foundation (NSF) requested that the U.S. Army Cold Regions Research and Engineering Laboratory (CRREL) establish a longterm record of surface albedo at the Pegasus and Phoenix Runway sites. To accomplish this, data from the National Aeronautics and Space Administration (NASA) Moderate Resolution Imaging Spectroradiometer (MODIS) satellite was used. MODIS satellite data has a daily temporal resolution and a significant period of record (2000-present). Additionally, its narrowband surface reflectance may be used as a proxy for albedo. This report documents the results of these analyses. 


\section{Contents}

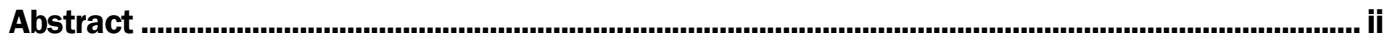

Figures and Tables........................................................................................................................iv

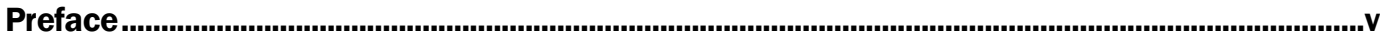

Acronyms and Abbreviations ............................................................................................................vi

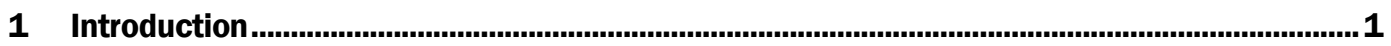

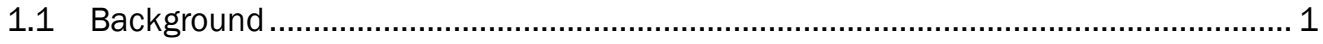

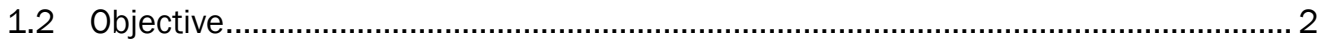

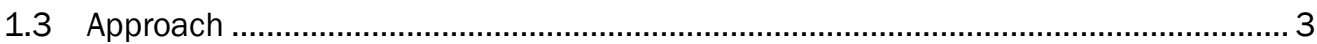

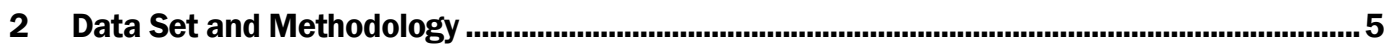

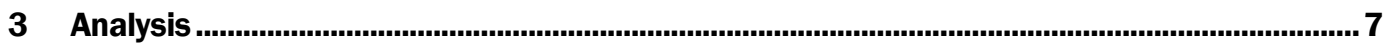

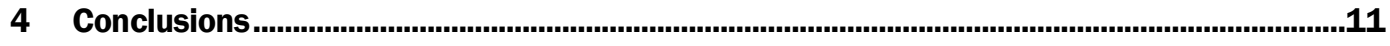

References .........................................................................................................................................13

Report Documentation Page 


\section{Figures and Tables}

\section{Figures}

1 DigitalGlobe WorldView-3 panchromatic (grayscale) satellite collection (25 November 2015) of the newly established Phoenix and existing Pegasus Runways. Green and red polygons represent the processing window for analysis (see Section 2)

2 MODIS pixels ( $500 \mathrm{~m}$, originally in sinusoidal projection) reprojected and displayed in WGS-84 (geographic projection) are illustrated by the blue grid (nonsquare pixels) overlaid on the DigitalGlobe Worldview-3 image from Fig. 1. To minimize distortion and errors in processing, map projection uses the native satellite collection geometry. Note that the image is flipped $180^{\circ}$ when compared to Fig. 1

3 Raster of pixel weights $\left(w_{n}\right)$, or the percentage of an overlapping pixel that is inside the surveyed extent of a runway (Phoenix Runway shown center, outlined in black, and re-projected in the MODIS sinusoidal projection; in this projection, the MODIS pixels appear square)

4 Solar spectral irradiance across the electromagnetic spectrum outside of the atmosphere (green) and at the Earth's surface (red). Discrete NASA MODIS satellite bands are highlighted in orange.

5 Average daily reflectance over 2000-2016 for pixels encompassing Phoenix (red) and Pegasus (blue) Runways for MODIS Band 3 (459-479 nm)

6 Average daily reflectance over 2000-2016 for pixels encompassing Phoenix (red) and Pegasus (blue) Runways for MODIS Band 4 (545-565 nm)

7 Average daily reflectance over 2000-2016 for pixels encompassing Phoenix (red) and Pegasus (blue) Runways for MODIS Band 1 (620-670 nm) 9

8 Average daily reflectance over 2000-2016 for pixels encompassing Phoenix (red) and Pegasus (blue) Runways for MODIS Band 2 (841-876 nm)

9 Monthly average reflectance over 2000-2016 for pixels encompassing Phoenix (red) and Pegasus (blue) Runways for MODIS Band 3 (459-479 nm)

10 Annual average reflectance over 2000-2016 for pixels encompassing Phoenix (red) and Pegasus (blue) Runways for MODIS Band 3 (459-479 nm) 


\section{Preface}

This study was conducted for the National Science Foundation (NSF), Office of Polar Programs (OPP), under Engineering for Polar Operations, Logistics, and Research (EPOLAR) EP-ANT-16-24, "Historical Albedo Assessment for Alpha Site Runway using Remote Sensing." The technical monitor was Margaret Knuth, NSF-OPP, U.S. Antarctic Program.

The work was performed by the Terrain and Ice Engineering Group (CEERD-RRC) of the Remote Sensing and Geographic Information Systems Center of Expertise (CEERD-RZR) and the Terrestrial and Cryospheric Sciences Branch (CEERD-RRG) of the Research and Engineering Division (CEERD-RR), U.S. Army Engineer Research and Development Center, Cold Regions Research and Engineering Laboratory (ERDCCRREL). At the time of publication, Mr. Stephen Newman was Chief, CEERD-RRC; Mr. David Finnegan was Director, CEERD-RZR; and CDRJ . D. Horne, USN (Ret.), was Chief, CEERD-RR. The Deputy Director of ERDC-CRREL was Dr. Lance Hansen, and the Director was Dr. J oseph L. Corriveau.

COL Bryan S. Green was Commander of ERDC, and Dr. David W. Pittman was the Director. 


\section{Acronyms and Abbreviations}

$\begin{array}{ll}\mathrm{CO}_{2} & \text { Carbon Dioxide } \\ \text { CRREL } & \text { Cold Regions Research and Engineering Laboratory } \\ \text { EPOLAR } & \text { Engineering for Polar Operations, Logistics, and Research } \\ \text { ERDC } & \text { U.S. Army Engineer Research and Development Center } \\ \text { EROS } & \text { Earth Resources Observation and Science } \\ \mathrm{H}_{2} \mathrm{O} & \text { Water } \\ \text { LP DAAC } & \text { Land Processes Distributed Active Archive Center } \\ \text { MODIS } & \text { Moderate Resolution Imaging Spectroradiometer } \\ \text { NASA } & \text { National Aeronautics and Space Administration } \\ \text { NSF } & \text { National Science Foundation } \\ \text { O } & \text { Ozone } \\ \text { USAP } & \text { U.S. Antarctic Program }\end{array}$




\section{Introduction}

\subsection{Background}

McMurdo is the main transportation hub for the U.S. Antarctic Program (USAP) on the Antarctic Continent. Passengers, equipment, and supplies are brought into McMurdo by vessel and air and then redistributed by air and overland traverse to the South Pole and Antarctic camps across the continent. In addition to a dock, McMurdo maintains airfields to support the movement of personnel and supplies into and out of Antarctica. At McMurdo, there are no easily accessible locations to place a runway directly on soil; as a consequence, the air operations into and out of McMurdo have relied on establishing and maintaining runways (for wheeled aircraft) and skiways (for ski equipped aircraft) on snow and ice.

In general, the integrity of the Pegasus and Phoenix Runways, both on the McMurdo Ice Shelf, depends on their strength, which is strongly influenced by the net heat transfer into the runway surface during the brief but intense peak of austral summer. The flux of downwelling shortwave solar energy is significant during the austral summer when 24-hour-per-day sunshine persists. The amount of this radiative flux absorbed by the runways is controlled by the albedo of the surface. During the 2012- 2013 and 2013- 2014 seasons, Pegasus Runway experienced significant reductions in the strength of the snow and ice layers that composed the runway, leading to extended shutdowns. In addition, during short warming trends that caused temporary reduction in the strength of the airfield, operations at the Pegasus Runway were shifted to the "night" when the sun was low in the sky and the ice was slightly colder and stronger. Longer warming trends led to the presence of liquid water on the runway surface, which significantly lowered the runway albedo. The formation of liquid water was a tipping point for runway conditions. After this point was reached, the runway degradation was rapid. These combined factors led to the decline in consistent operations at Pegasus Runway and ultimately the replacement of Pegasus Runway with the Phoenix Runway in the 2016- 2017 field season (Daly et al. 2015; Haehnel et al. 2013).

Impurities such as dust, soot, mineral, and organic deposits on a snow or ice surface also lowers the surface albedo, increasing solar energy absorption. This increased energy uptake can initiate melting of the snow; and as 
mentioned above, the presence of melt water in the snow further reduces albedo and increases heating of the snow, further reducing pavement strength and promoting more melting. To prevent or delay reaching the melt tipping point, it is critical to maintain the albedo of the snow surface as high as possible. Based on some qualitative analysis from ground observations and contemporary satellite imagery of the impacts of impurities, a new location (referred to as Phoenix) was identified for airfield construction as it is generally further away from a zone of increased dust deposition and closer to a zone of increased snow accumulation (Haehnel et al. 2014).

\subsection{Objective}

Because of the operational difficulties of the Pegasus Runway and construction of the new Phoenix Runway, the National Science Foundation (NSF) requested that the U.S. Army Cold Regions Research and Engineering Laboratory (CRREL) establish a long-term record of surface albedo at the two runway sites (Figure 1).

Figure 1. DigitalGlobe WorldView-3 panchromatic (grayscale) satellite collection (25 November 2015) of the newly established Phoenix and existing Pegasus Runways. Green and red polygons represent the processing window for analysis (see Section 2).

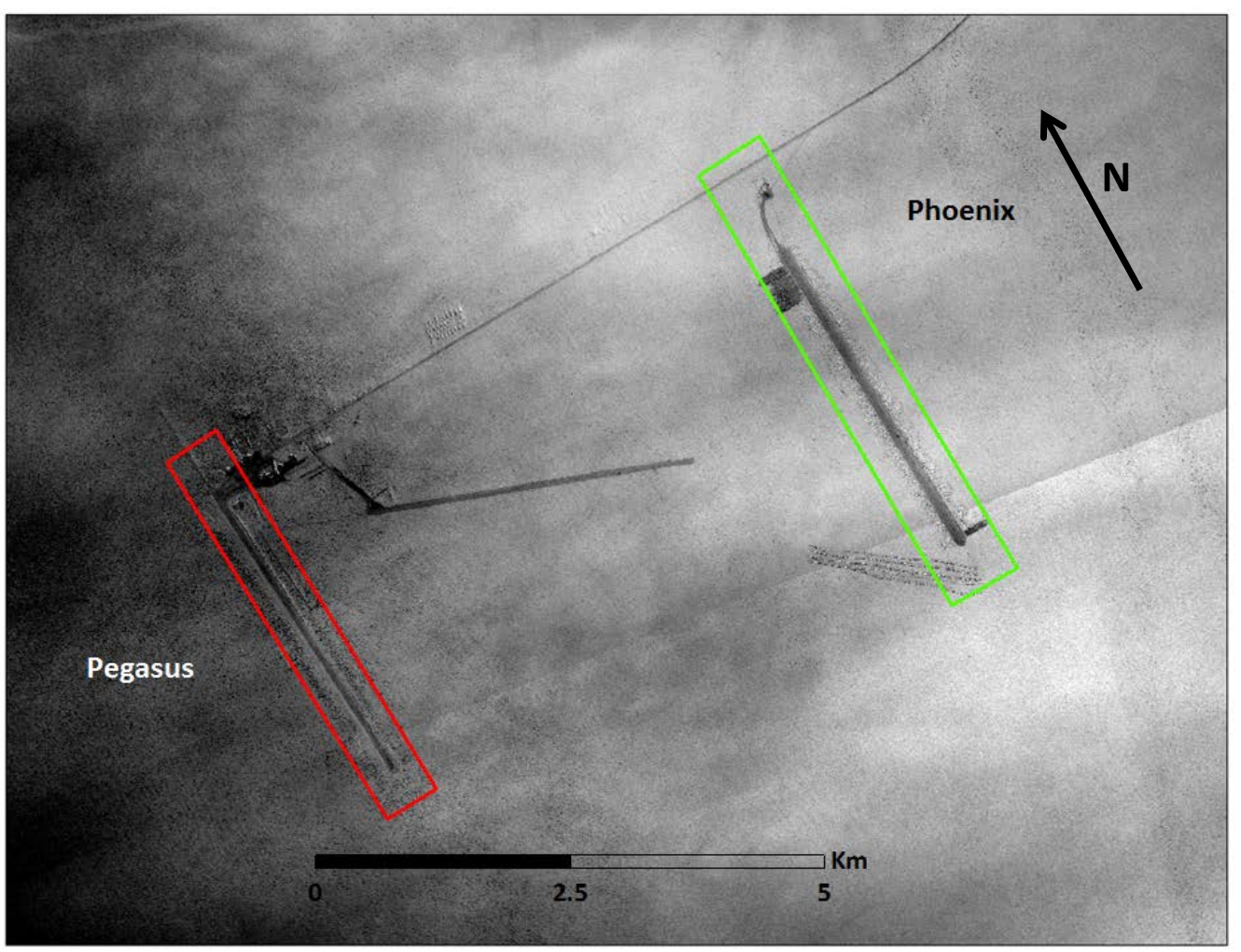




\subsection{Approach}

Spectral albedo, $\alpha(\lambda)$, is defined as the ratio of total hemispherical reflected (upwelling) to incoming (downwelling) radiative flux (or irradiance) at a surface at a specific wavelength, $\lambda$ :

$$
\alpha(\lambda)=\frac{F_{u}(0, \lambda)}{F_{d}(0, \lambda)}
$$

where

$$
\begin{aligned}
\mathrm{F}_{\mathrm{u}} & =\text { the upwelling radiative flux; } \\
\mathrm{F}_{\mathrm{d}} & =\text { the downwelling radiative flux; and } \\
0 & =\text { the surface. }
\end{aligned}
$$

For operations on the McMurdo Ice Shelf, Antarctica, the total albedo, or broadband albedo, $\alpha_{\mathrm{t}}$, is of more interest as it is a measure of the total energy absorbed by the ice or snow surface. This is found in terms of the spectral albedo as (Perovich 1996)

$$
\alpha_{t}=\frac{\int \alpha(\lambda) F_{d}(0, \lambda) d \lambda}{\int F_{d}(0, \lambda) d \lambda} .
$$

In application, this equation is integrated over the solar (or shortwave) radiation band (approximately 300-3000 nm) to estimate the broadband albedo.

This study explores using the National Aeronautics and Space Administration's (NASA) Moderate Resolution Imaging Spectroradiometer (MODIS) satellite data to determine temporal changes in surface albedo at the Pegasus and Phoenix Runway sites. MODIS was chosen because of its temporal resolution (daily) and extensive period of record (2000- present). The MODIS sensor suite exists onboard both the NASA Terra and Aqua satellites. MODIS Terra data are presented here as MODIS Aqua data showed similar results. We did learn that, unfortunately, the MODIS land-surface albedo products (MCD43A3) are not available because the region of interest encompassing the Pegasus and Phoenix Runways has been masked out (flagged as ocean) from the processing given its location on the Ross Ice Shelf, which floats on the McMurdo Sound. 
Because of this limitation, MODIS's narrowband surface reflectance (which could be evaluated as individual products or as an aggregate, broadband reflectance) was used as a proxy for albedo. As previously stated, albedo is the ratio of the irradiance reflected from the surface (leaving at all angles) to the total irradiance striking the surface from the entire hemisphere above (incoming radiation at all angles) at all wavelengths. By contrast, reflectance is the ratio of reflected radiation observed from a particular viewing angle (the sensor zenith) and illuminated from a particular direction (the solar azimuth and zenith). Additionally, in the case of imaging sensors, reflectance measurements are limited to bands or wavelength ranges. Despite these differences, reflectance and albedo are closely related. Satellite-based albedo products are constructed using reflectance data (Strahler and Muller 1999). Because collection swaths overlap slightly and shift predictably with time (MODIS Terra cycles through its orbital pattern every 16 days), each day there are several observations of each ground location, each with a different sensor and solar geometry (and different from the preceding and succeeding day). By aggregating 16 days of data and interpolating over all possible angles, end member albedo cases ("white sky" and "black sky") can be modeled. The actual albedo or "blue sky" albedo falls somewhere in between the end members and is dependent on the wavelength range, optical depth, aerosol type, and solar angle (Strahler and Muller 1999). Because albedo is derived from reflectance, we assume that it may be used as a proxy if considered across several wavelength ranges (bands), particularly over longer time periods ( $>16$ days). In general, reflectance values should follow the same trend as albedo, though the magnitude of albedo and reflectance may differ. 


\section{Data Set and Methodology}

The raw MODIS data are initially collected as a swath product (considered a Level 1 product) in a grid that is aligned and unique to the path of the sensor. Higher-level products are reprojected to a "standard grid," which is very distorted at high latitudes. For example, this study used the MODIS Surface Reflectance Product (Level 2, product name: MOD09GA), which is postprocessed into a sinusoidal projection with a pixel size (at the equator) of approximately $463 \mathrm{~m}$ (NASA LP DAAC 2016). At the extreme latitude of the study site ( $\left.77^{\circ} 51^{\prime} \mathrm{S}\right)$, there is, necessarily, a significant difference and distortion in the layout of the swath data and that of the Level 2 sinusoidal projection, whose ground footprint tapers to a singularity at the poles (NASA LP DAAC 2016). Figure 2 illustrates the distortion in these pixels by the comparison to WGS- 84 .

Figure 2. MODIS pixels ( $500 \mathrm{~m}$, originally in sinusoidal projection) reprojected and displayed in WGS-84 (geographic projection) are illustrated by the blue grid (nonsquare pixels) overlaid on the DigitalGlobe Worldview-3 image from Fig. 1. To minimize distortion and errors in processing, map projection uses the native satellite collection geometry. Note that the image is flipped $180^{\circ}$ when compared to Fig. 1.

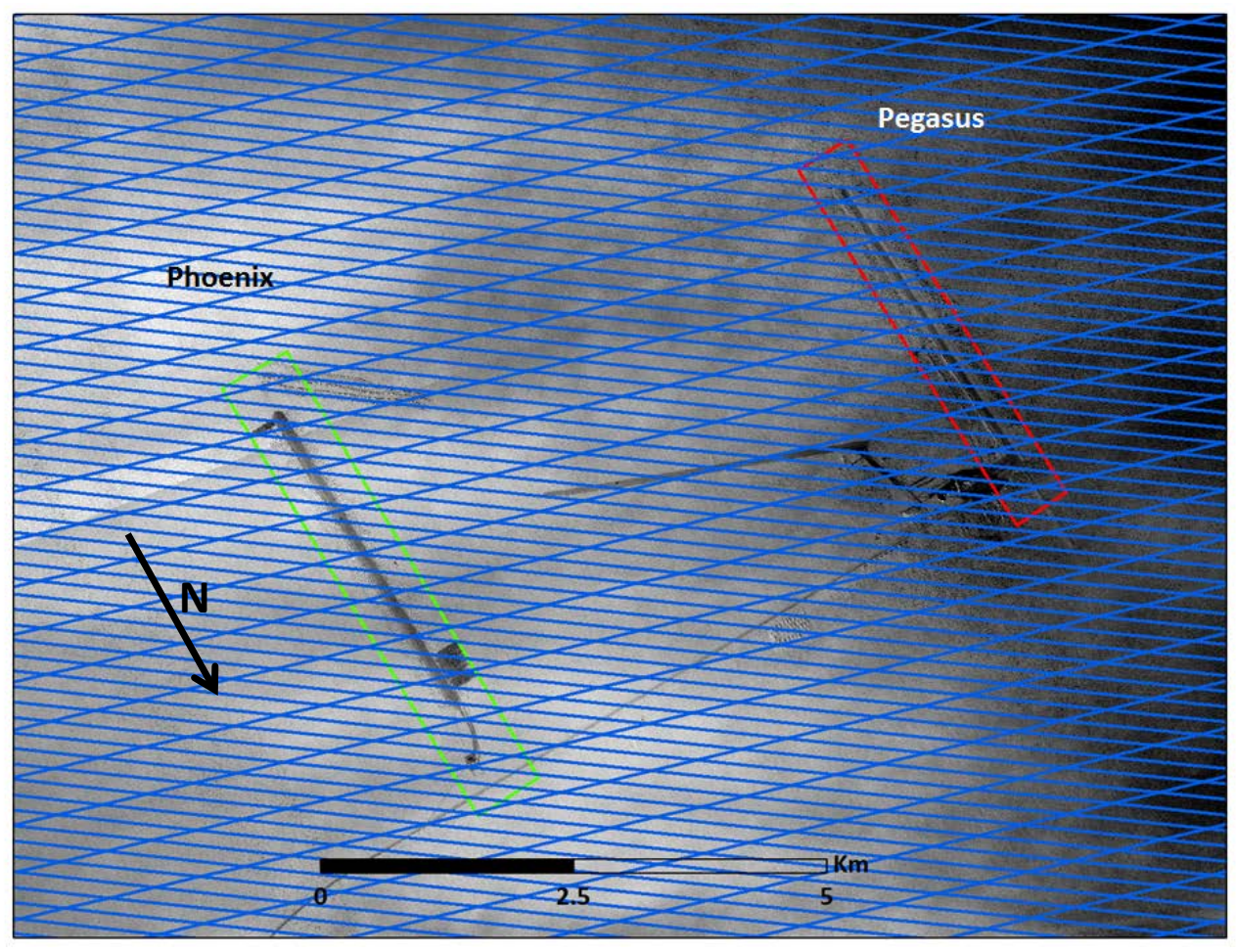

To mitigate potential error caused by this resampling and to provide a more holistic view of the reflectance over each of the Pegasus and Phoenix 
Runways, we averaged reflectance over the pixels that intersected the digitized extent of each runway; however, because of the orientation of the pixels involved (Figure 2), a simple average of overlapping pixels is not representative of each runway's reflectance but instead of a much larger area. To address this, we calculated the percentage of each pixel that actually overlapped the surveyed extent of the runway (Figure 3) and used that percentage to weigh that pixel's contribution to the runway average:

$$
R_{r}=\frac{\sum_{n=1}^{p} w_{n} R_{n}}{\sum_{n=1}^{p} w_{n}}
$$

where

$\mathrm{R}_{\mathrm{r}}=$ the percentage reflectance of pixel overlapping runway;

$\mathrm{R}_{\mathrm{n}}=$ the reflectance of pixel $\mathrm{n}$;

$\mathrm{W}_{\mathrm{n}}=$ the fraction of pixel $\mathrm{n}$ that overlaps the runway; and

$\mathrm{p}=$ the subset of pixels for each individual runway that are cloudfree, high-quality data. Data quality is determined from the MODLAND_QA “00" flag in the NASA MODIS Terra (MOD09GA) and Aqua (MYD09GA) reflectance products.

Note that this is equivalent to a simple average if, for all pixels, $\mathrm{wn}_{\mathrm{n}}=1$.

Figure 3. Raster of pixel weights $\left(w_{n}\right)$, or the percentage of an overlapping pixel that is inside the surveyed extent of a runway (Phoenix Runway shown center, outlined in black, and re-projected in the MODIS sinusoidal projection; in this projection, the MODIS pixels appear square).

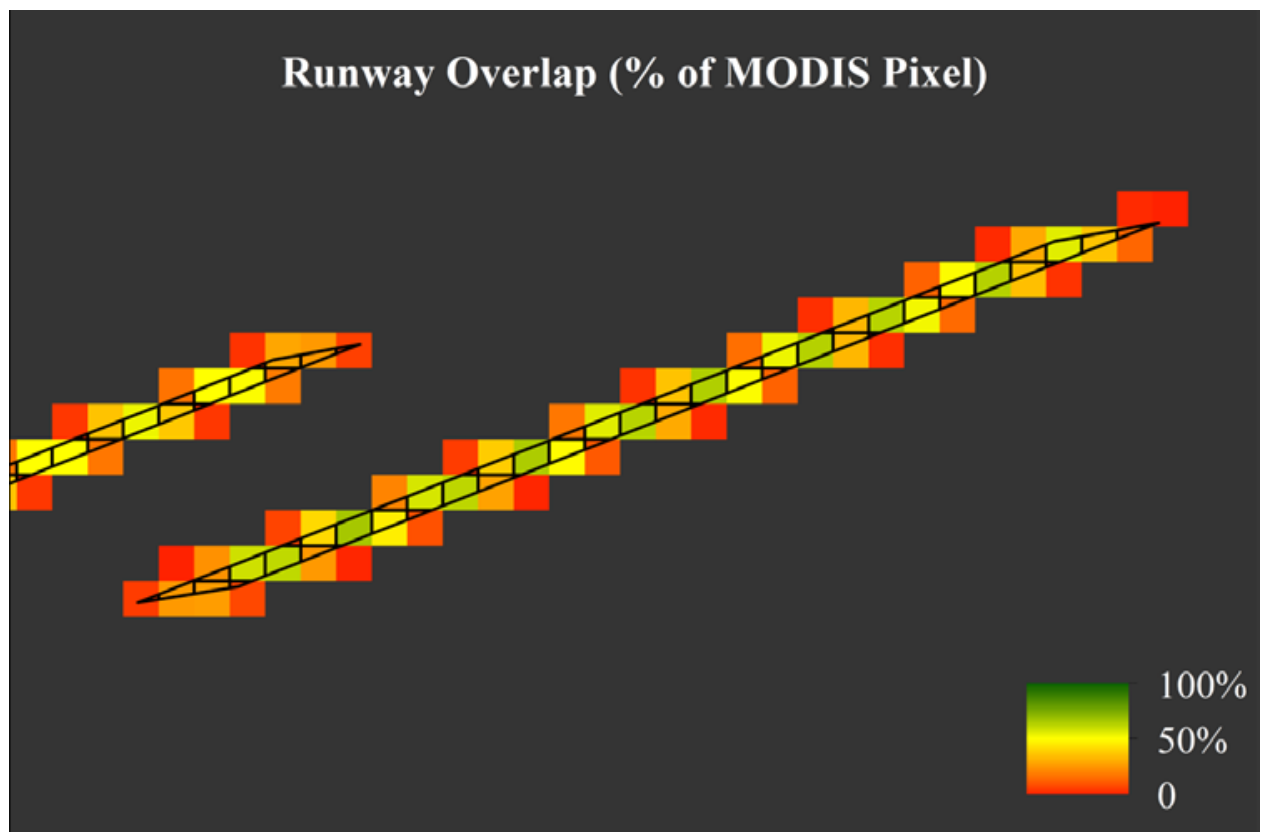




\section{Analysis}

The surface temperature of the sun generally characterizes the solar spectrum. This spectrum defines the spectral irradiance across all wavelengths of radiation as the Earth's atmosphere reduces the solar irradiance that reaches the Earth's surface. Ozone $\left(\mathrm{O}_{3}\right)$, water vapor $\left(\mathrm{H}_{2} \mathrm{O}\right)$, and carbon dioxide $\left(\mathrm{CO}_{2}\right)$ absorb this radiation at certain wavelengths. Multispectral satellites generally leverage regions of the electromagnetic spectrum outside of these absorption bands (atmospheric windows) where transmission is greatest through the atmosphere. Figure 4 depicts the solar irradiance outside of the atmosphere, the direct solar irradiance at the Earth's surface, and the NASA MODIS spectral bands that typically leverage the atmospheric windows of transmission. This study analyzed MODIS bands 3 , 4,1 , and 2 (listed in order of increasing wavelength) as narrowband and broadband analogues to albedo based on the highest relative amounts of solar irradiance.

Figure 4. Solar spectral irradiance across the electromagnetic spectrum outside of the atmosphere (green) and at the Earth's surface (red). Discrete NASA MODIS satellite bands are highlighted in orange.

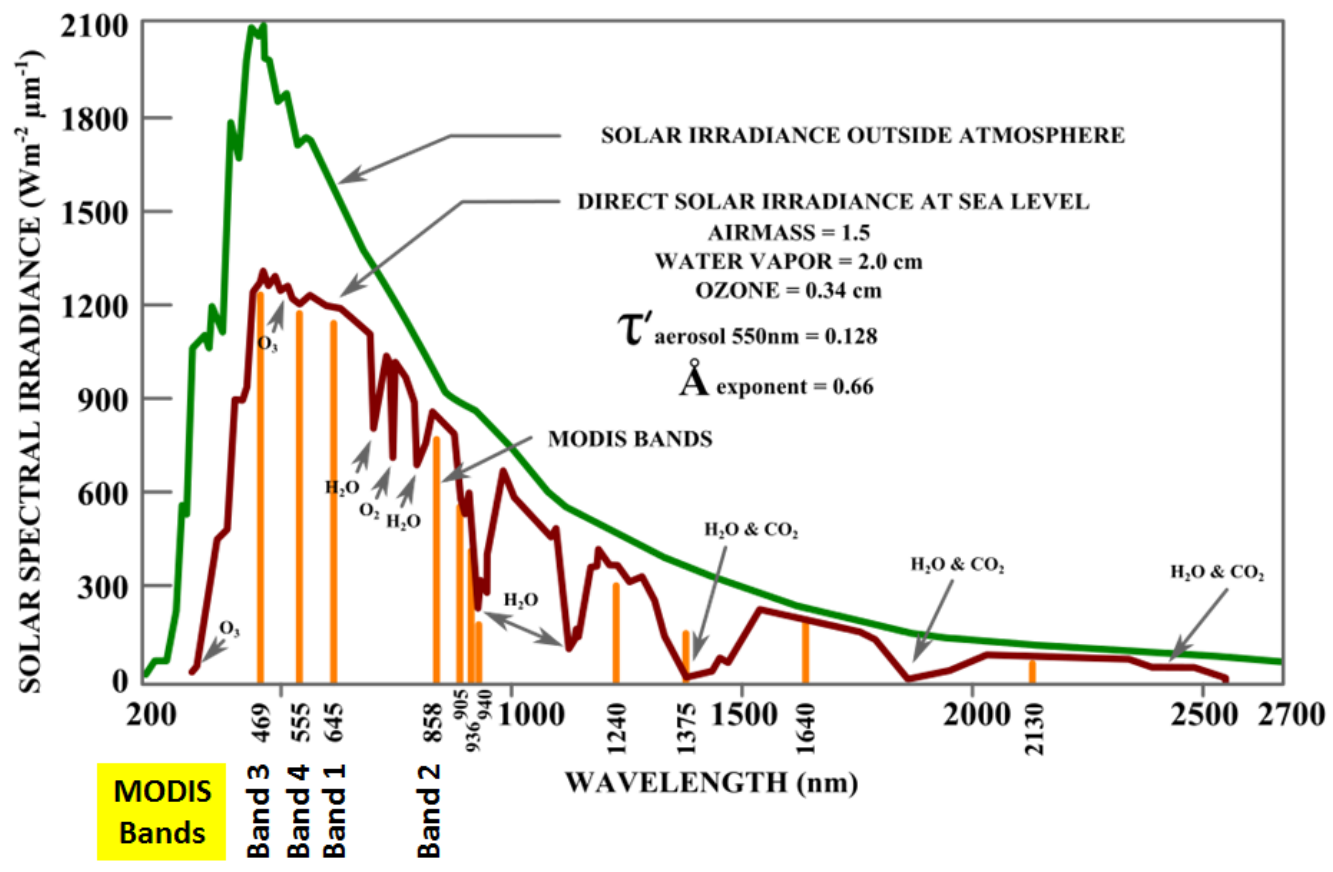

For available MODIS Terra satellite observations, Figures 5- 8 highlight the average daily reflectance for the period of record (2000-2016) by us- 
ing the processing methodology for calculating representative pixel percentages as explained in the previous section. The figures show for the following spectral ranges the results of pixels encompassing both the Phoenix and Pegasus runways: 459- $479 \mathrm{~nm}$ (MODIS Band 3), 545- $565 \mathrm{~nm}$ (MODIS Band 4), 620-670 nm (MODIS Band 1), and 841- $876 \mathrm{~nm}$ (MODIS Band 2).

In general, for each MODIS band, the pixels encompassing the Phoenix Runway exhibit a higher surface reflectance than the pixels encompassing the Pegasus Runway. This is analogous to higher surface albedo across the broadband wavelengths. Moreover, these data are consistent with the solar spectral irradiance curves in Figure 4 such that shorter wavelengths show relatively higher spectral reflectance than longer wavelengths for both runways based on the corresponding higher solar spectral irradiance at shorter wavelengths.

Figure 5. Average daily reflectance over 2000-2016 for pixels encompassing Phoenix (red) and Pegasus (b/ue) Runways for MODIS Band 3 (459-479 nm).

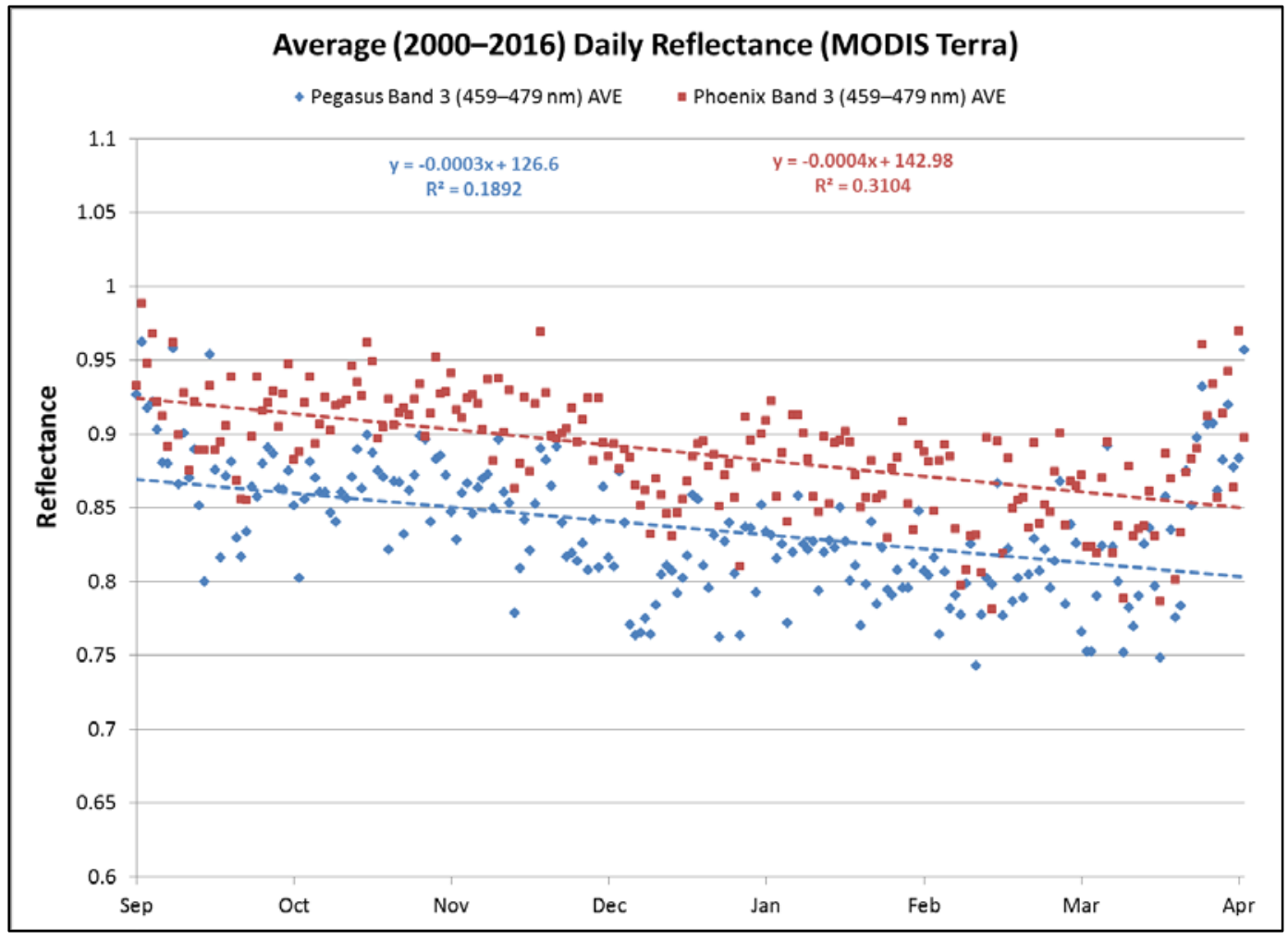


Figure 6. Average daily reflectance over 2000-2016 for pixels encompassing Phoenix (red) and Pegasus (b/ue) Runways for MODIS Band 4 (545-565 nm).

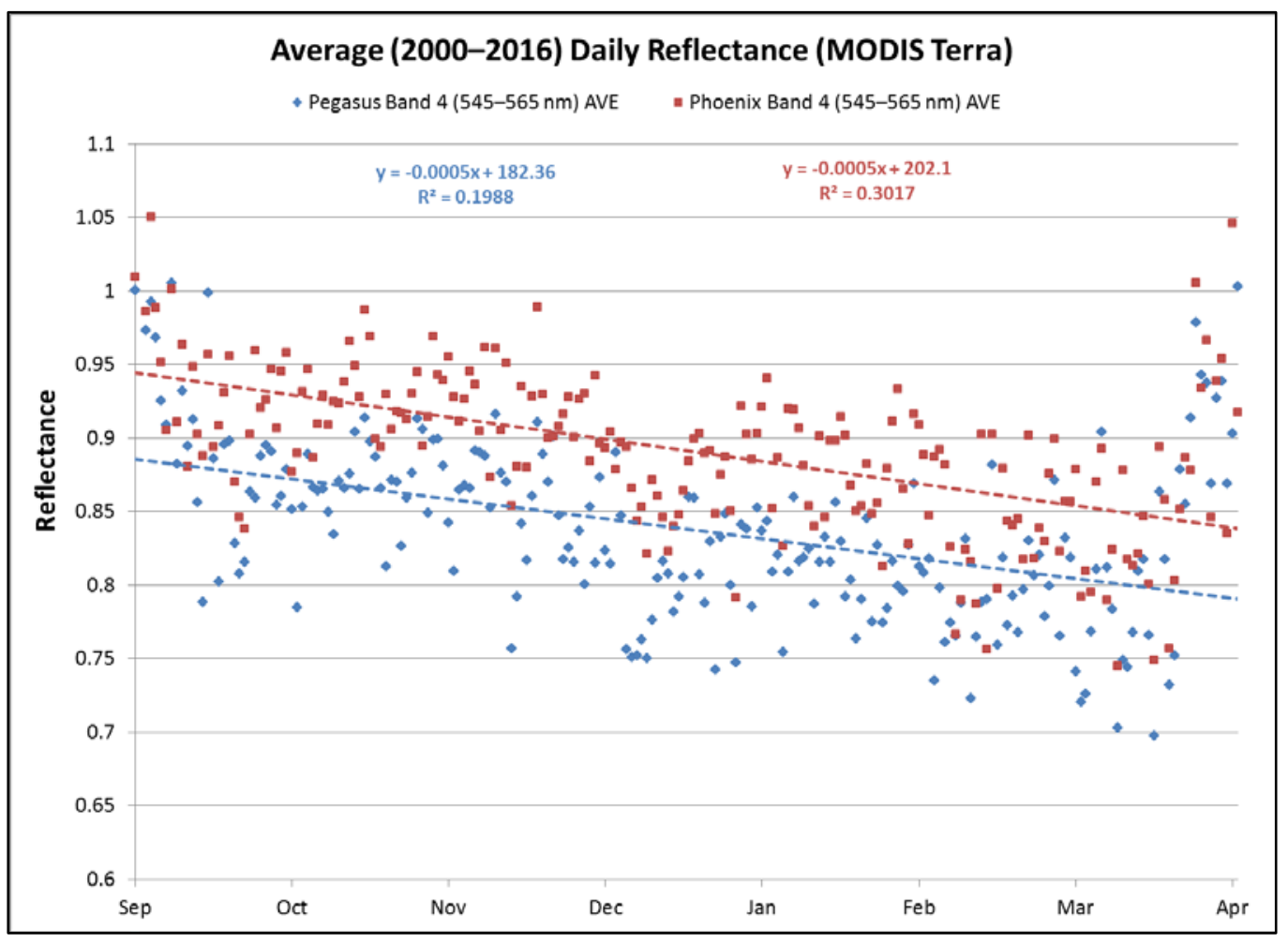

Figure 7. Average daily reflectance over 2000-2016 for pixels encompassing Phoenix (red) and Pegasus (b/ue) Runways for MODIS Band 1 (620-670 nm).

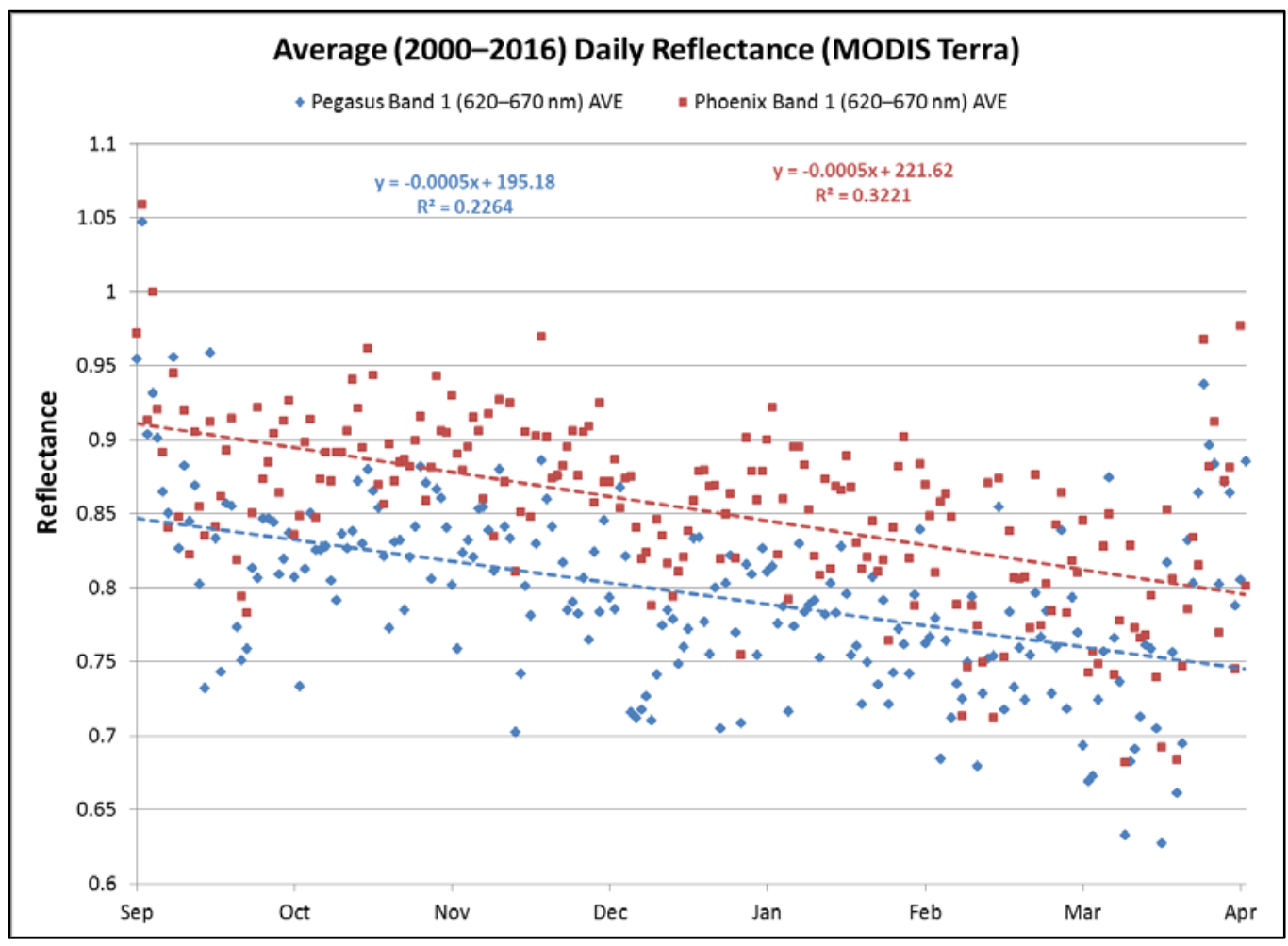


Figure 8. Average daily reflectance over 2000-2016 for pixels encompassing Phoenix (red) and Pegasus (b/ue) Runways for MODIS Band 2 (841-876 nm).

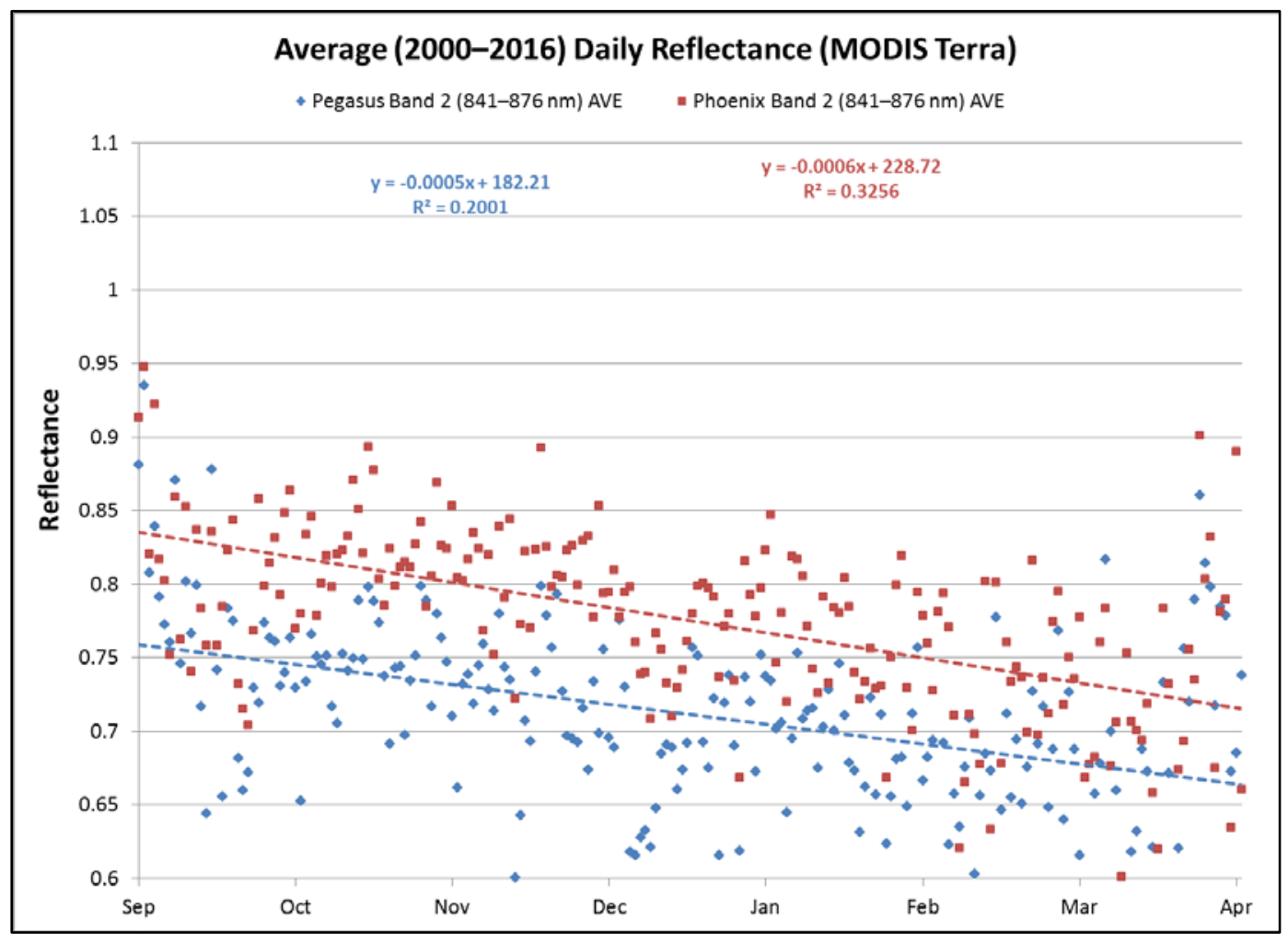




\section{Conclusions}

We found that over the period of observation (2000-2016), the MODIS data showed that generally the broadband reflectance, and by analogy albedo, is higher at the Phoenix site than at the Pegasus Runway. While it is difficult to directly compare these satellite observations to the range of albedo from fresh Antarctic snow and bare blue or sea ice, these results are reasonable when compared to other general studies of snow and ice albedo as well as Antarctic specific studies (Gardner and Sharp 2010; Wuttke et al. 2006). The MODIS data shows obvious seasonal variations in the albedo with the highest albedo observed in the spring (September), a steady decline through the summer, and a rebound in late March and early April (Figure 9). This is to be expected as summer snowmelt and metamorphosis of the snow pack will reduce the albedo of snow.

Figure 9. Monthly average reflectance over 2000-2016 for pixels encompassing Phoenix (red) and Pegasus (b/ue) Runways for MODIS Band 3 (459-479 nm).

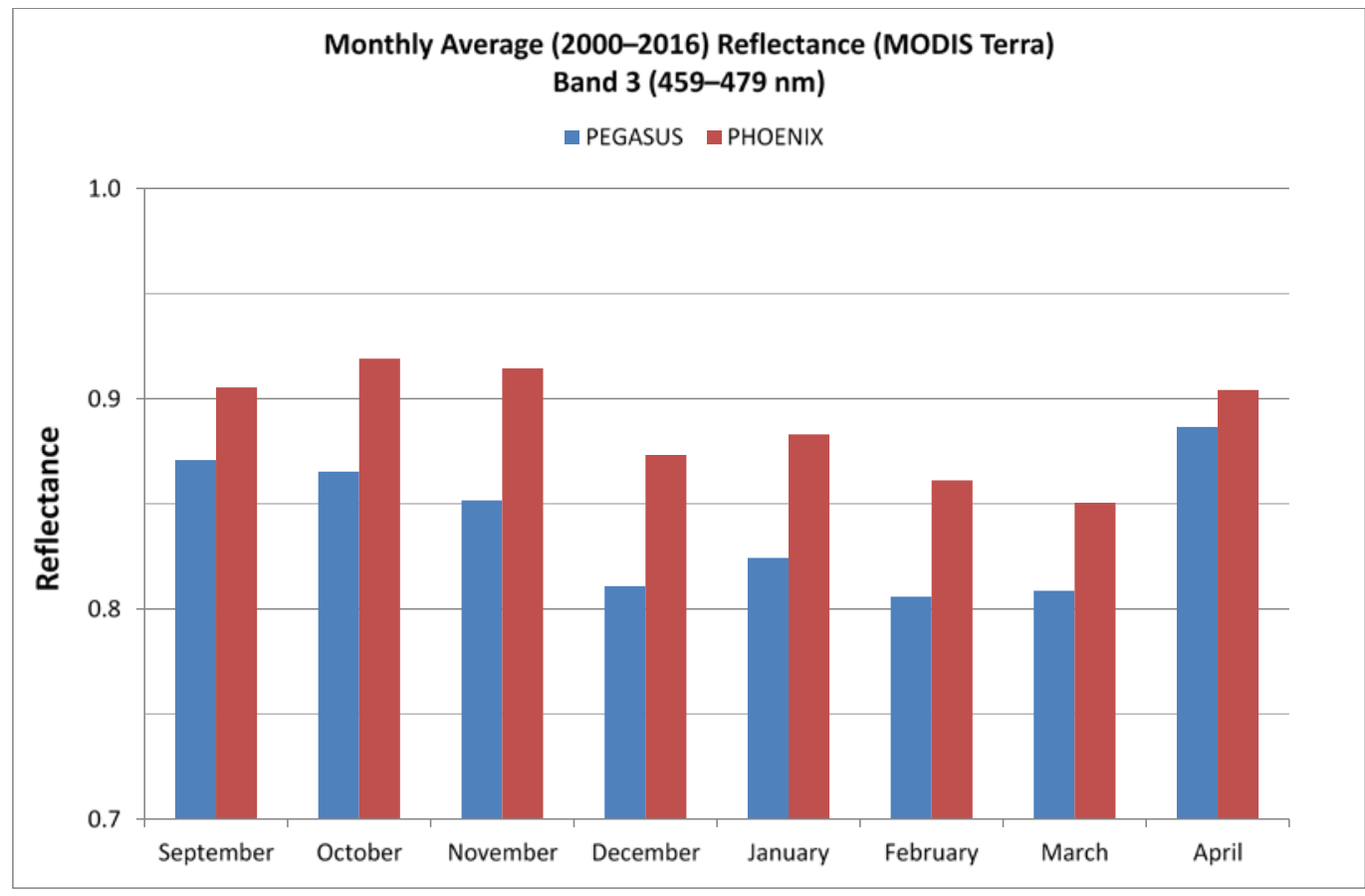

In Figure 10, the MODIS data also show that both sites have shown a steady, but slow, downward annual trend in albedo from 2000 to 2012. There appears to be a more rapid decline in albedo at Pegasus from 2013 to 2016. A similar, but less pronounced decline in albedo may also be occurring at the Phoenix site likewise starting in about 2013. Additional 
analysis is required to assess the significance of these trends and how they may persist in future operational seasons.

Figure 10. Annual average reflectance over 2000-2016 for pixels encompassing Phoenix (red) and Pegasus (b/ue) Runways for MODIS Band 3 (459-479 nm).

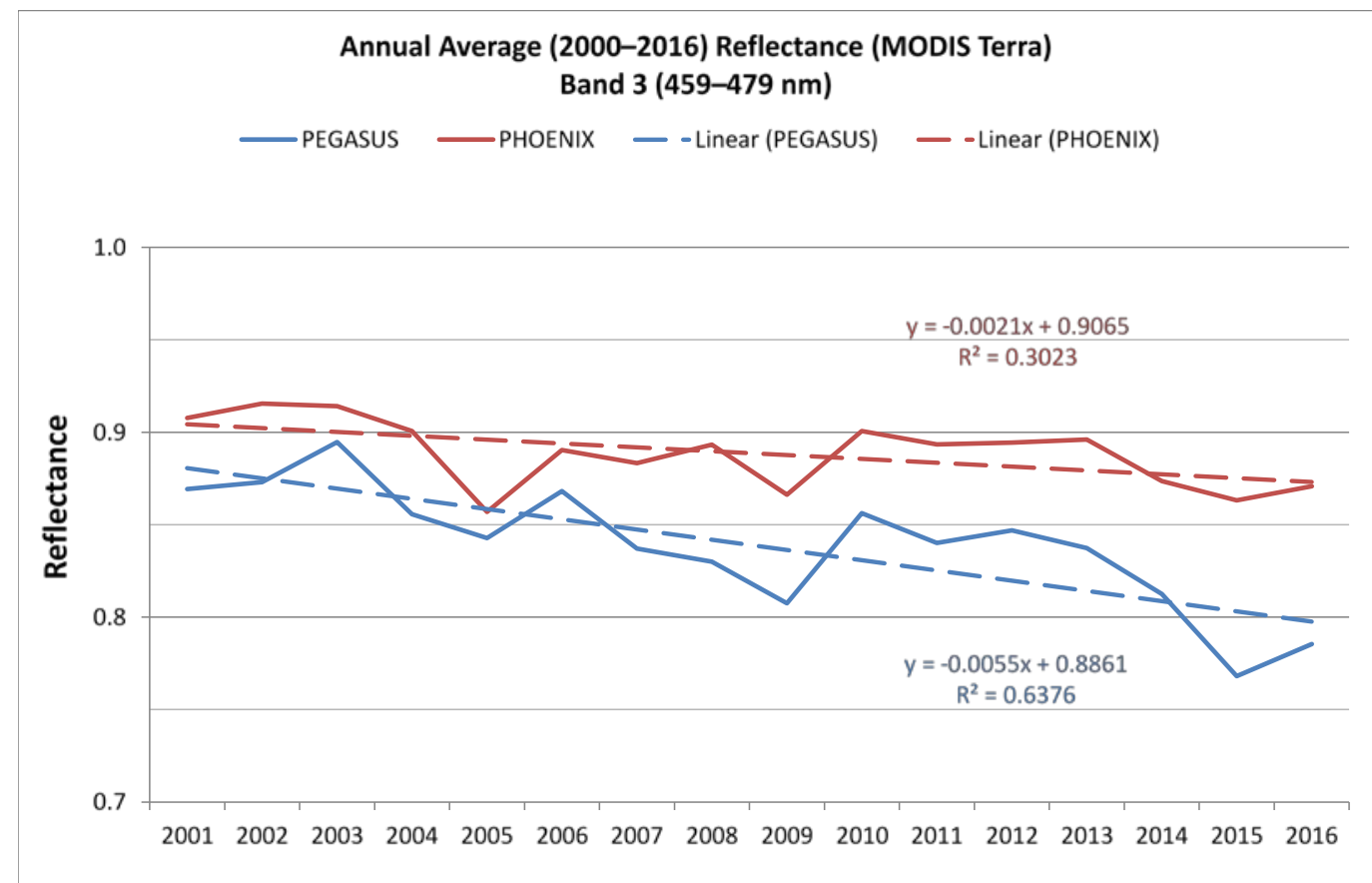

Additional work may also include (1) further investigation of how well broadband MODIS reflectance bands estimate trends in snow albedo and (2) whether changes in albedo may be leveraged toward estimating when the melt tipping point of the runway is reached at each site. Challenges exist overcoming the coarse spatial resolution of the satellite (MODIS 500 meters) and optical methods being impacted by cloud-cover. This results in a noisy signal (both spatially and temporally) and requires a statistical approach performed over a time series (seasonal to decadal). Additional, consistent in-situ observations of albedo and melt conditions are required to determine whether this type of satellite remote sensing technique can link lowered surface reflectance and surface melt toward a runway maintenance quality control tool. 


\section{References}

Daly, S. F., R. Haehnel, C. Heimstra. 2015. Vertical Temperature Simulation of Pegasus Runway, McMurdo Station, Antarctica. ERDC/CRREL TR-15-1. Hanover, NH: U.S Army Engineering Research and Development Center.

Gardner, A. S., and M. J . Sharp. 2010. A Review of Snow and Ice Albedo and the Development of a New Physically Based Broadband Albedo Parameterization. J ournal of Geophysical Research 115:F01009. doi:10.1029/2009J F001444.

Haehnel, R. B., K. Bjella, M. A. Knuth, and L. Barna. 2013. McMurdo Consolidated Airfields Study: Phase I, Basis of Design. ERDC/ CRREL TR-13-5. Hanover, NH: U.S. Army Engineer Research and Development Center.

Haehnel, R., M. A. Knuth, T. Melendy, C. Hiemstra, and R. Davis. 2014. Design and Implementation of a Consolidated Airfield at McMurdo, Antarctica. ERDC/CRREL TR-14-22. Hanover, NH: U.S. Army Engineer Research and Development Center.

NASA LP DAAC (National Aeronautics and Space Administration's Land Processes Distributed Active Archive Center). 2016. MODIS Level 1 Surface Reflectance Daily L2G Global 500m. Version 5. Sioux Falls, South Dakota: NASA Earth Observing System Data and Information System Land Processes Distributed Active Archive Center, U.S. Geological Survey Earth Resources Observation and Science (EROS) Center. https://e4ftl01.cr.usgs.gov/MOLT/MOD09A1.005/ (accessed 1 January 2016).

Perovich, D. K. 1996. The Optical Properties of Sea Ice. CRREL Monograph 96-1. Hanover, NH: U.S. Army Cold Regions Research and Engineering Laboratory.

Strahler, A. H., and J . P. Muller. 1999. MODIS BRDF/ Albedo Product: Algorithm Theoretical Basis Document. Version 5.0. Washington, DC: National Aeronautics and Space Administration.

Wuttke, S., G. Seckmeyer, and G. König-Langlo. 2006. Measurements of Spectral Snow Albedo at Neumayer, Antarctica. Annals of Geophysics 24:7- 21. doi:10.5194/angeo-24-7-2006. 


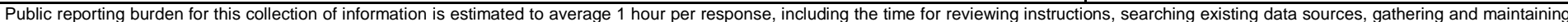

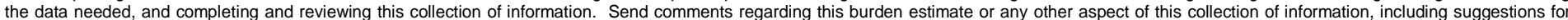

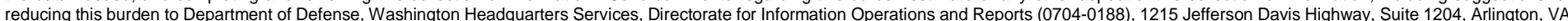

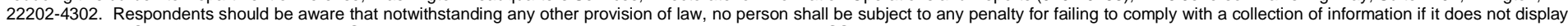
a currently valid OMB control number. PLEASE DO NOT RETURN YOUR FORM TO THE ABOVE ADDRESS.

\begin{tabular}{l|l}
$\begin{array}{l}\text { 1. REPORT DATE (DD-MM-YYYY) } \\
\text { July } 2017\end{array}$ & $\begin{array}{l}\text { 2. REPORT TYPE } \\
\text { Technical Report/Final }\end{array}$ \\
\hline
\end{tabular}

\section{TITLE AND SUBTITLE}

Changes in the Albedo of the Pegasus and Phoenix Runways, 2000-2017

3. DATES COVERED (From - To)

5a. CONTRACT NUMBER

EP-ANT-16-24

5b. GRANT NUMBER

5c. PROGRAM ELEMENT NUMBER

\section{AUTHOR(S)}

Elias J. Deeb, Blaine F. Morriss, Steven F. Daly, and Robert B. Haehnel 5d. PROJECT NUMBER

5e. TASK NUMBER

5f. WORK UNIT NUMBER

8. PERFORMING ORGANIZATION REPORT NUMBER

ERDC/CRREL TR-17-10

10. SPONSOR/MONITOR'S ACRONYM(S)

NSF

11. SPONSOR/MONITOR'S REPORT NUMBER(S)

National Science Foundation, Office of Polar Programs,

Antarctic Infrastructure and Logistics

Arlington, VA 22230

12. DISTRIBUTION I AVAILABILITY STATEMENT

Approved for public release; distribution is unlimited.

\section{SUPPLEMENTARY NOTES}

Engineering for Polar Operations, Logistics, and Research (EPOLAR)

\section{ABSTRACT}

Albedo is the ratio of total hemispherical reflected (upwelling) to incoming (downwelling) radiative flux (or irradiance) at a surface. For operations on the McMurdo Ice Shelf, Antarctica, albedo is a controlling factor. Impurities such as dust, soot, mineral, and other organic deposits on a snow or ice surface can dramatically lower albedo, increase solar energy absorption in the ice shelf, and significantly alter the energy balance, resulting in increased melting, snow density variations, and compromised structural integrity of the snow and ice matrix. The occurrence of such impurities at Pegasus Runway may have been a factor in its decline and replacement with the Phoenix Runway in the 2016-2017 field season. Therefore, the National Science Foundation (NSF) requested that the U.S. Army Cold Regions Research and Engineering Laboratory (CRREL) establish a long-term record of surface albedo at the Pegasus and Phoenix Runway sites. To accomplish this, data from the National Aeronautics and Space Administration (NASA) Moderate Resolution Imaging Spectroradiometer (MODIS) satellite was used. MODIS satellite data has a daily temporal resolution and a significant period of record (2000-present). Additionally, its narrowband surface reflectance may be used as a proxy for albedo. This report documents the results of these analyses.

\section{SUBJECT TERMS}

EPOLAR, Heat--Transmission, McMurdo Ice Shelf (Antarctica), NSF, Remote-sensing images, Runways, Snow albedo, Solar radiation

\section{SECURITY CLASSIFICATION OF:}

\section{a. REPORT}

Unclassified

\section{b. ABSTRACT}

Unclassified c. THIS PAGE

Unclassified
17. LIMITATION OF ABSTRACT

SAR
18. NUMBER OF PAGES

22 19a. NAME OF RESPONSIBLE PERSON

19b. TELEPHONE NUMBER (include area code) 